\title{
O “PROJETO COLUMBIA” - UM RESGATE NECESSÁRIO
}

\author{
Josildeth Gomes Consorte ${ }^{1}$
}

\begin{abstract}
RESUMO
O texto ocupa-se da análise de um programa de pesquisas de quatro pequenas comunidades baianas, desenvolvido entre 1949 e 1952, por iniciativa do Dr. Anísio Teixeira, Secretário de Educação e Saúde do Estado, a fim de obter subsídios para sua atuação. O programa teve início num anteprojeto elaborado pelo professor Charles Wagley, do departamento de Antropologia da Universidade de Columbia com a colaboração de Eduardo Galvão, etnólogo do Museu Nacional (Rio de Janeiro) e foi dirigido por uma comissão integrada pelo professor Wagley, por Dr. Thales de Azevedo (da secretaria de Educação e Saúde) e pelo professor Luiz Aguiar da Costa Pinto, da Universidade do Brasil. A pesquisa de campo foi conduzida por quatro equipes chefiadas cada uma delas por um doutorando em Antropologia da Universidade de Columbia, auxiliado por estudantes brasileiros. Dos quatro estudos, apenas três foram concluídos, sendo transformados em teses de doutorado e publicados. Apesar da repercussão que o programa alcançou nos meios acadêmicos, sua contribuição em termos de subsídios para ação na área de Educação e Saúde ficou aquém do esperado, razão do seu resgate.
\end{abstract}

Palavras-chave: Anísio Teixeira; Charles Wagley; Thales de Azevedo; Universidade de Columbia.

\section{THE "COLUMBIA PROJECT" - A NECESSARY RESCUE}

\begin{abstract}
The article analyses a research program on four small communities located at the State of Bahia, carried out between 1949 and 1952 due to the initiative of Dr. Anísio Teixeira while State Secretary of Education and Health, in order to give support to his work. The Program was outlined by Professor Charles Wagley, from Columbia University Department of Anthropology with the collaboration of Eduardo Galvão ethnologist at the Museu Nacional. It was conducted by a board of directors including Professor Wagley, Dr. Thales de Azevedo representing the State Secretary of Education and Professor Luiz Aguiar da Costa Pinto from the Universidade do Brasil. The field research was the responsibility of four graduate Columbia University students of anthropologist helped by undergraduate Brazilian students. Only three of these studies were concluded and published as Ph Thesis. The Program was a success among social scientists. Nevertheless, did not contribute that much for the specific problems of education and health as expected one of the reasons for being revisited.
\end{abstract}

Key Words: Anísio Teixeira; Charles Wagley; Thales de Azevedo; Columbia Project.

O "Projeto Columbia", intitulado na sua origem, em 1949, "Programa de Pesquisas Sociais Estado da Bahia - Columbia University", foi mais uma das muitas iniciativas pioneiras na educação, características do modo de pensar e agir do Dr. Anísio Teixeira, então secretário de Educação e Saúde do Estado da Bahia do governo de Octávio Mangabeira. 
Foi contemporâneo da Escola Parque (o Centro Educacional "Carneiro Ribeiro") experimento educacional ainda hoje lembrado e revisitado pelo que representou em termos de realização efetiva do seu projeto educacional - a escola nova - junto à população de baixa renda de Salvador. É, no entanto talvez, o menos conhecido, dos seus projetos, não obstante o entusiasmo que despertou no momento, os recursos humanos e materiais que mobilizou e os frutos que produziu,

O Programa de Pesquisas Sociais, instalado inicialmente num prédio em frente à Secretaria de Educação, faria parte do programa de ação da Fundação para o Desenvolvimento da Ciência da Bahia, criada em 1950, órgão que deveria assumir esta e outras iniciativas no campo específico da formação de quadros e produção de conhecimento. Teria, em pouco tempo, sede própria no bairro da Graça, não muito longe dali. Educação e desenvolvimento - um binômio perseguido com muito denodo ao longo de sua vida - caminhavam, assim, juntos naquela gestão. A descoberta da sua existência e o interesse em conhecê-lo por parte de educadores é coisa recente. Nosso país tem pouca memória.

O programa teve início num anteprojeto, elaborado entre 1948 e 1949, a pedido de Dr. Anísio, pelo professor Charles Wagley, do departamento de Antropologia da Universidade de Columbia, em New York, com a cooperação de Eduardo Galvão, etnólogo do Museu Nacional (Rio de Janeiro) então concluindo seu doutorado em antropologia naquela universidade. Tendo em vista os objetivos do Dr. Anísio, consistia num plano para estudos de comunidades em áreas rurais do estado da Bahia com a finalidade de oferecer, a partir da pesquisa científica, conhecimentos sobre a sociedade e a cultura daquelas regiões que pudessem dar subsídios à sua atuação nas áreas da educação e da saúde.

Os Estudos de comunidade eram, naquele momento, a ponta de lança da Antropologia americana na sua abordagem das chamadas sociedades complexas, apoiada na tradição, em que se formara, de estudos das sociedades nativas. Alguns trabalhos e autores já haviam se tornado clássicos neste particular dentre eles, o professor Robert Redfield, da universidade de Chicago, com seu trabalho na Península de Yucatán, já amplamente conhecido.

Os estudos chamados de comunidades, com que na segunda década deste século a Antropologia iniciou sua investigação de sociedades complexas, tiveram grande aceitação entre nós ·e deram origem a uma série de trabalhos que, sob aquela denominação, começaram a ser feitos no Brasil, nos últimos dez anos. A preocupação inicial desses estudos foi a de mostrar a aplicabilidade das técnicas de pesquisa antropológica, até então usadas sàmente no estudo de grupos primitivos, ao estudo das culturas de que participavam os próprios estudiosos. Partia-se do pressuposto de que, sendo o fenômeno cultural um só em espécie, no estudo de suas manifestações, quer entre primitivos, quer entre civilizados, era possível a aplicação das mesmas técnicas. (GOMES, 1956)

A mudança e o desenvolvimento, palavras de ordem daquele momento, não só no Brasil, mas no mundo, deveriam acontecer, não apenas nos modos de vida vigentes, mas também no modo de atuar politicamente dos governantes, através do conhecimento empírico, científico das populações que estariam participando destes processos. O passamento da sociedade tradicional era tido como um fenômeno irreversível. 
As relações do Dr. Anísio com a Universidade de Columbia eram antigas e marcantes. Obtivera seu mestrado no Teacher's College, em 1928, onde fora aluno de John Dewey e W. Kilpatrick que influenciaram profundamente sua formação e ampliaram enormemente seu interesse pela educação. Um verdadeiro divisor de águas em sua existência, antes orientada por um projeto de vida a serviço da Igreja na Ordem de Santo Inácio de Loyola.

As relações do Prof. Wagley com o Brasil não o eram menos. Seu primeiro contato com o país ocorrera já em 1938, ano em que chegou ao Rio de Janeiro, com mais três colegas antropólogos da Universidade de Columbia, uma viagem promovida pelo Museu Nacional do Rio de Janeiro, então sob a direção de dona Heloisa Alberto Torres, em conseqüência da Política de Boa Vizinhança dos Estados Unidos com a América Latina em vigor. Desta vez estudaria os índios Tapirapé, junto aos quais passaria cerca de oito meses.

Com o início da $2^{\mathrm{a}}$. Guerra, voltou aos Estados Unidos retornando ao Brasil em 1941, já casado, para lecionar no Museu Nacional e orientar estudantes numa pesquisa de campo entre os índios Tenetehara, do Maranhão.

Voltou ao Brasil outras vezes, no exercício de diferentes funções. Seu casamento com Cecília Roxo, de conceituada família carioca, contribuíra sem dúvida para selar definitivamente seus vínculos com o país.

Em 1942, um convênio de cooperação Brasil/ Estados Unidos levou-o à Amazônia, junto com a esposa, para um programa de assistência à população pobre da região: mineradores, seringueiros e imigrantes das secas que lá se achavam.

Quando do convite de Dr. Anísio para a elaboração do aludido projeto de estudos da realidade baiana, acabara de concluir seu trabalho na Amazônia, auxiliado por Eduardo Galvão, do qual resultariam duas publicações. (WAGLEY, 1977 e GALVÃO, 1955) Parecia alguém talhado para a missão.

Coincidentemente, um outro programa de estudos de comunidade de grande envergadura tinha início à mesma época, sob a direção do Prof. Donald Pierson da Universidade de Chicago, então diretor da Escola de Sociologia e Política de São Paulo, voltado para o vale do Rio São Francisco, das suas nascentes à sua foz, abrangendo áreas dos estados de Minas Gerais, Bahia, Alagoas, financiado pelo Smithsonian Institute.

O projeto do Vale do São Francisco não tinha como objetivo específico oferecer subsídios para orientar o trabalho dos administradores em relação à educação e saúde, mas aprofundar o conhecimento daquela região através da metodologia que tais estudos permitiam.

Dr. Thales de Azevedo, uma fonte fidedigna, informa num depoimento sobre Dr. Anísio que o mesmo chegara a convidar o Dr. Pierson para encarregar-se do seu Projeto na Bahia, que por razões de trabalho não pode aceitar a incumbência (AZEVEDO, 1992).

Não era a primeira vez que Dr. Anísio exercia o cargo de responsável maior pela educação no estado da Bahia. Sua primeira investidura se dera, cerca de 20 anos antes (1925-1928) no governo Góes Calmon quando, sem qualquer experiência neste particular, mas altamente respeitado por sua inteligência e sólida formação humanística, foi nomeado Diretor da Instrução daquele estado e elaborou seu primeiro projeto destinado a reformar o ensino. As medidas propostas não agradaram a todos e o descontentamento gerado angariou seus primeiros opositores.

O segundo momento de Dr. Anísio à frente da educação do estado (agora acoplada à saúde), foi representado pelo Programa de Pesquisas Sociais que ora revisitamos, cujo pioneirismo na busca do concurso das Ciências Sociais para a pesquisa sobre a vida social 
e cultural das comunidades atendidas pelas escolas, sobretudo das relações entre elas, ainda hoje não é difícil avaliar.

A importância das relações entre a escola e a comunidade já estava explicita e enfaticamente colocada no Manifesto dos Pioneiros da Educação Nova (AZEVEDO et al, 1932).

À escola antiga, presumida da importância do seu papel e fechada no seu exclusivismo acanhado e estéril, sem o indispensável complemento e concurso de todas as outras instituições sociais, se sucederá a escola moderna aparelhada de todos os recursos para estender e fecundar a sua ação na solidariedade com o meio social, em que então, e só então, se tornará capaz de influir, transformando-se num centro poderoso de criação, atração e irradiação de todas as forças e atividades educativas.

Ninguém ignora que a escola só existe porque existe uma comunidade, a que se destina. Ninguém ignora também, que a escola funciona a partir de normas e conteúdos que não são ditados pela comunidade, que são elaboradas em instâncias de poder muito distantes dela, a partir de um projeto político de âmbito nacional, voltado para a construção de um denominador comum que o Estado deseja tornar patrimônio de cada cidadão.

Todavia, a escola, por onde todos devem passar e durante algum tempo conviver é o espaço da diversidade (física, biológica e cultural, de gênero, idade, origem social pertencimentos étnicos, religiosos, diversidade de talentos, competências, aptidões etc.).

E a diversidade, ao mesmo tempo que é fonte de riqueza, facilmente pode se transformar em sinônimo de desigualdade e fonte de discriminação. A diversidade contém "o outro", diferente de mim. Como levar ou auxiliar o outro a crescer a despeito das minhas idiossincrasias, das barreiras que a alteridade coloca entre nós/crianças, adolescentes e professores(as)?

Conhecer e respeitar a diversidade parecia ser o caminho pelo qual todos poderiam ter iguais oportunidades na escola. As ciências sociais eram, sem dúvida, uma via pela qual esta diversidade poderia ser melhor compreendida valorizada e usada a favor de todos.

A coordenação do Programa foi confiada a uma equipe composta pelos professores Charles Wagley, da Universidade de Columbia, Thales de Azevedo, da Universidade da Bahia (representando a Fundação) e Luis Aguiar da Costa Pinto, do Instituto de Economia da Fundação Mauá e da Universidade do Brasil, convidado pelo Dr. Anísio e pelo professor Wagley, diretor geral do Programa.

As pesquisas de Campo, propriamente ditas, seriam realizadas por três doutorandos em antropologia da Universidade de Columbia: Mavin Harris, Benjamim Zimmerman e Harry Hutchinson, orientandos do prof. Wagley, auxiliados por estudantes universitários brasileiros de Salvador e do Rio de Janeiro das áreas de humanas (geografia, história e Ciências Sociais), dentre os quais me encontrei, tendo preparado mesmo, para a ocasião, um texto sobre uma das regiões a serem pesquisadas (Gomes, 1952).

Os recursos para a realização do Programa viriam de duas fontes: do governo do Estado (em moeda nacional) e da Universidade de Columbia e de outras organizações científicas americanas (em dólares).

Para as despesas de viagem à Salvador, os três doutorandos receberam bolsas (os dois primeiros do Social Science Research Coincil, e o terceiro da Doherty Foundation). O prof. Wagley, por sua vez recebeu um auxilio do Conselho de Pesquisas em Ciências Sociais da Universidade de Columbia e do Viking Found. O professor Costa Pinto foi licenciado de seu cargo no Instituto Mauá, recebendo, ainda, um subsídio para fins de participação na coordenação do projeto. 
As despesas na Bahia (hospedagem, moradia, alimentação, deslocamento, material de consumo, equipamentos, fotos, etc.) seriam cobertas pelo Estado. O depósito inicial do governo baiano em junho de 1950 foi de 250 mil cruzeiros, seguido de verbas suplementares, totalizando aproximadamente, ao final de 1951, Cr\$750.000,00 (setecentos e cinqüenta mil cruzeiros).

Ao longo do ano anterior ao início da pesquisa de campo (junho de 1949/ junho 1950) todo um trabalho preliminar foi realizado tanto em Salvador quanto na Universidade de Columbia. Em Columbia, além dos esforços individuais dos doutorandos para aprendizado da língua portuguesa, um seminário no Departamento de Antropologia incumbiu-se de prepará-los no sentido de conhecer a região em que iriam trabalhar e aprofundar-se na metodologia dos estudos de comunidade. Em Salvador, por sua vez, o prof. Thales incumbiu-se de reunir, com o nosso auxilio (então sua estudante) dados considerados indispensáveis ao trabalho (demográficos, econômicos, administrativos, jurídicos etc.) e providenciar a infra-estrutura (material e de pessoal) necessária à instalação e funcionamento das equipes.

A pesquisa foi também precedida de um estudo cuidadoso do Estado da Bahia pela equipe dirigente, a fim de dividi-la em zonas ecológicas, a partir das quais seriam escolhidas as comunidades para estudo. Seis zonas ecológicas resultaram desta divisão (o Recôncavo, o Sertão do Nordeste, as Florestas do sul, o Planalto Central, o Vale do São Francisco e o Planalto Ocidental) três das quais foram escolhidas "aquelas mais intimamente ligadas social e economicamente com a cidade de Salvador", o Recôncavo, o Planalto Central e o Sertão do Nordeste. (WAGLEY, C., AZEVEDO, T., COSTA PINTO, 1950).

Em cada uma delas, foram escolhidas duas comunidades, uma representando os modos tradicionais de vida da região e outra, considerada como "progressista" e "moderna", para comparação com a primeira. Assim foram selecionadas: no Planalto Central, as cidades de Rio de Contas (tradicional) e Livramento de Brumado (progressista); no Sertão do Nordeste, as cidades de Monte Santo (tradicional) e Euclides da Cunha (progressista); no Recôncavo, a cidade de São Francisco do Conde (tradicional) e um povoado formado por trabalhadores de uma grande usina industrial de açúcar (Usina São João).

Junho de 1950, com a chegada do prof. Wagley e dos seus estudantes pesquisadores, foi um momento de grande entusiasmo, confraternização e expectativa por parte de todos os envolvidos. Era um acontecimento a ser realmente comemorado numa Salvador de vida intelectual ainda pacata, naqueles anos. Depois de alguns dias de adaptação, várias reuniões e um seminário com a participação de Dr. Anísio, assessores, intelectuais convidados, de muita troca de informações e experiências, cada pesquisador seguiu com seu auxiliar brasileiro para sua comunidade de destino onde deveria passar um ano, segundo o cânone dos estudos de comunidade, realizando seu trabalho. Para todos, uma experiência inesquecível de aprendizado profissional e de convívio com "o outro", tão caro à antropologia.

A fase de campo teve início em junho/julho de 1950 e foi concluída dois anos depois, em meados de 1952.

Do campo, os pesquisadores enviavam relatórios bimestrais (se não me engano) e, a cada três meses, realizava-se um seminário com toda a equipe (pesquisadores, auxiliares, coordenadores, Dr. Anísio) para discussão do andamento do projeto.

Em Janeiro de 1951, uma visita importante, vinda da UNESCO, Dr. Alfred Metraux, etnólogo e velho conhecido do Brasil, foi portadora de um convite, aos olhos de todos, irrecusável, para que o Programa de Pesquisas Sociais, em curso, encampasse a pesquisa 
sobre relações raciais que aquele órgão desejava fazer na Bahia como parte de um projeto de grande envergadura, que abrangeria outras regiões do país, tal projeto fora colocado na agenda daquele órgão por Arthur Ramos, notável antropólogo brasileiro, recém-falecido, quando coordenador do seu departamento de Ciências Sociais, em 1949.

As relações raciais, que já haviam despontado como um aspecto relevante da vida social nas três comunidades, ganharam assim uma situação privilegiada nas preocupações dos pesquisadores. Foi o único aspecto da vida das três comunidades que ganhou um tratamento à parte, integrando uma publicação da UNESCO pouco depois de concluído o programa do Dr. Anísio. (WAGLEY, 1952). A educação, ainda que contemplada aqui e ali nas suas pesquisas, esteve longe de merecer a mesma atenção.

Dos três estudos de comunidade iniciados em junho de 1950, apenas dois foram levados a término (o do Planalto Central e o do Recôncavo). Um ano mais tarde, em junho de 1951, mais um estudo seria acrescentado ao programa, desta vez, na zona do Cacau, com sede em Uruçuca, sob a responsabilidade de Antony Leeds, outro doutorando da Universidade de Columbia. Transformados em teses de doutorado, seriam publicados em diferentes momentos, alguns anos depois (HARRIS, 1956; HUTCHINSON, 1957; LEEDS, 1968), o que não quer dizer que todo o material colhido tenha sido analisado.

O término do Programa de Pesquisas em meados de 1952, coincidiu, aproximadamente, com a ida de Dr. Anísio para o Rio de Janeiro para assumir a direção do Instituto Nacional de Estudos Pedagógicos (INEP) e a coordenação da Campanha de Aperfeiçoamento de Pessoal de Nível Superior (CAPES), ambas no Ministério da Educação, a convite do também baiano Dr. Simões Filho, então ministro da Educação.

Todo seu acervo, incluindo os relatórios enviados do campo pelos pesquisadores, foi incorporado à Fundação para o Desenvolvimento da Ciência na Bahia que prosseguiu em outras atividades, inclusive amparando pesquisas de estudiosos baianos tanto na Bahia como fora dela, até desaparecer em 1967, quando se criou a Secretaria de Ciência e Tecnologia do Estado, conforme depoimento de Thales de Azevedo (AZEVEDO, 1992), sem nunca ter sido extinta.

Depois do golpe de 1964, o acervo desapareceu e nenhuma publicação conclusiva em termos dos subsídios para a educação e a saúde na Bahia, esperados dos estudos de comunidade, resultou de todo aquele esforço, que, não obstante, resultaria em outros ganhos (WAGLEY, 1970).

Como diretor do INEP no Ministério da Educação no Rio de Janeiro, Dr. Anísio criaria o Centro Brasileiro de Pesquisas Educacionais (CBPE) ao qual se seguiriam alguns Centros Regionais onde a pesquisa continuaria a orientar seus passos.

Num texto de 1956, já como pesquisadora do CBPE, ao fazer um balanço da contribuição do conjunto dos estudos de comunidades já realizados entre nós, para a educação, chego às seguintes conclusões:

1. Para que os estudos de comunidades realmente contribuam ao máximo para o conhecimento da complexidade das sociedades nacionais e dos seus problemas, eles precisam ir além da simples apresentação de um quadro geral da vida das comunidades, do traçado de um perfil, ou da descrição do entrelaçamento de suas instituições num nível apenas local. Eles precisam, efetivamente, analisá-las em termos da estrutura nacional de que participam. Somente dessa perspectiva acreditamos poder chegar a uma compreensão do cenário nacional. Alguns dos estudos considerados infelizmente não supriram esta lacuna. 
2. A compreensão das diferentes coordenadas que entram em jogo na formação de uma comunidade já seria, por si só, um critério na determinação do que seria ou não relevante para o seu estudo e, conseqüentemente, para a seleção do material a ser colhido. A consideração da posição administrativa das comunidades estudadas, por exemplo, teria sido por si só suficiente para a compreensão de certas instituições nelas encontradas da forma com que estas instituições se apresentaram, assim como do seu maior ou menor grau de estruturação. Teria no mínimo indicado o caminho a seguir na colocação das mesmas na perspectiva mais ampla em que precisavam ser encaradas.

3. No que se refere à escola, em face das situações que neste trabalho discutimos, a necessidade de que tome consciência da realidade que representa, parece-nos fundamental. Se de um lado ela é instituição nacional e representa uma certa ordem de valores, de outro lado, ela precisa atuar em contextos sociais locais diversos e heterogêneos. Se, como instituição nacional, ela supõe uma política e uma teoria de educação, na prática a interferência de um sem número de variáveis se incumbe de transformar aquela orientação e amoldá-la em sentidos não previstos.

4. A escola precisaria, pois, estar consciente:

I - do seu papel de instrumento de mudança e de integração das diversas populações sobre as quais atua, na sociedade maior a que as mesmas pertencem;

II - da diversidade de expectativas e de solicitações que se criam à sua volta e da sempre presente possibilidade de sua identificação com um desses grupos de interesse em detrimento dos demais, prejudicando assim a realização dos seus objetivos;

III - dos valores, conceitos e atitudes locais que, divergindo dos seus, podem contrariar, em parte ou totalmente, as próprias bases do ensino;

IV - da sua condição de grupo cuja composição é frequentemente heterogênea e no qual, estando muitas vezes em jogo interesses diversos, é constantemente ameaçada a obra educativa a que em ideal se propõe;

V - em suma, da sua condição de instituição a que está confiado um programa, mas para a realização do qual a dinâmica interna do grupo social que a concretiza e a de suas relações com o ambiente que o cerca podem se tornar elementos positivos ou negativos e sensivelmente modificá-lo. (GOMES, 1956)

Uma pergunta se impõe na conclusão deste texto: que significado tem o silêncio sobre o Projeto Columbia e sua invisibilidade tanto para as Ciências Sociais como para a Educação? À guisa de resposta, ousamos sugerir que:

1- Apesar do interesse que despertaram, nos anos 1940 e 1950, entre antropólogos e sociólogos desejosos de conhecer o Brasil na sua intimidade, com o tempo os estudos de 
comunidade perderam sua importância face à necessidade de novas perspectivas teóricometodológicas para a análise da nova realidade que emergiu a partir dos anos de 1960.

Quinze anos depois do seu início, os problemas colocados pela realidade brasileira estavam longe de poder ser equacionados por eles, exigindo outros quadros de referência para serem entendidos. A polaridade da qual se partira para os estudos de comunidades não dera conta das realidades estudadas. Ao contrário, atrapalhara a compreensão. Alguns estudos revelam uma percepção de dois brasis como coisas estanques, um vivendo da rotina, outro dinâmico, agitado pela civilização. O "atraso" do mundo rural enfocado por tais estudos parecia não ter nada a ver com o sistema abrangente que articulava as relações econômicas, sociais e políticas que hegemonizavam o conjunto da sociedade brasileira e que respondia pelo nome de modo de produção capitalista. Não é sem razão que nenhum estudo de comunidade, salvo engano, a ele faz referência. Enquanto os estudos em questão iam sendo realizados, as contradições geradas pelas mudanças se aprofundavam e iam fazendo surgir uma consciência nova da natureza dos nossos problemas, indicando, por exemplo, que o arcaico, o tradicional, o rústico radicavam na questão da terra e que só uma reforma agrária poderia mudar a sorte dos pequenos produtores rurais, que seu "atraso" não encontraria solução em nível local, que a problemática do país era de sub-desenvolvimento, de capitalismo dependente, como se dizia então, e como tal, de outra natureza (CONSORTE, 1996).

2- Os antropólogos pesquisadores, mais preocupados talvez com as peculiaridades de cada comunidade, não conseguiram ver a escola em cada uma delas na sua especificidade local, ou seja, como elas se realizavam em cada lugar, tratando-a como algo que vinha de fora e, consequentemente, sem muito interesse para o seu trabalho, ainda que solicitado por um educador.

3- A falta de participação de professores e diretores de escola, ausentes involuntariamente da discussão e desenvolvimento do Programa, reforçando a tradicional distância entre o mundo da escola e o mundo extramuros, intensificando a percepção de que o desconhecimento deste continua a não fazer diferença ao alcance dos seus objetivos, ainda que a realidade não cesse de mostrar o contrário.

\section{Referências}

AZEVEDO, Fernando de [et al.] "Manifestos dos Pioneiros da Educação Nova". (1932) disponível em http://www.histedbr.fae.unicamp.br/revista/edicoes/22e/doc1_22e.pdf;

AZEVEDO, Thales. "Depoimento de Dr. Thales de Azevedo" in: ROCHA João Augusto L. "Anísio em Movimento - A vida e as lutas de Anísio Teixeira pela Escola Pública e pela Cultura no Brasil" - Ed. Fundação Anísio Teixeira, (1992). disponível em http://www.bvanisioteixeira.ufba.br/livro6/depoimento_129.html; 
CONSORTE, Josildeth G. "Os Estudos de Comunidades no Brasil: uma viagem no tempo" in: Humanismo e Compromisso: Ensaios sobre Octávio Ianni, Editora da UNESP, São Paulo. (1996);

GALVÃO, E. "Santos e Visagens". São Paulo: Companhia editora Nacional - Col. Brasiliana, v. 284. (1955);

GOMES, Josildeth S. "Povoamento da Chapada Diamantina" Comunicação ao II Congresso de História da Bahia, jun. (1952);

GOMES, Josildeth S. "A Educação nos Estudos de Comunidade no Brasil" Revista Educação e Ciências - Ano I, vol.1, n² - pag. 65 (1956);

HARRIS, Marvin. "Town and Contry in Brazil", New York: Columbia University Press. (1956);

HUTCHINSON, H. "Village and Plantantion life in northeastern Brazil", Seattle, University of Washington Press, (1957);

LEEDS, Antony. "Economic Cycles in Brazil: The Persistence of a Total-Culture Pattern: Cacao and Other Cases" - Annarbor University of Michigan. Micro-films Service, (1968);

WAGLEY, Charles. "Race and class in rural Brazil”, Paris: UNESCO. (1952); . “Uma Comunidade Amazônica”. [1955]. Companhia Editora Nacional: São Paulo. (1977). $\quad$ e Belo Horizonte: Itatiaia. (1988).

WAGLEY, C., AZEVEDO, T., COSTA PINTO, Luiz A. "Uma pesquisa sobre a vida social no Estado da Bahia", publicação do Museu do Estado, no. 11, - Secretaria da Educação e Saúde - Bahia, (1950).

WAGLEY, Charles e Cecília, "Serendipity in Bahia" - Universitas 6/7, Salvador: maio/dez. (1970).

Notas

${ }^{1}$ Professora doutora, titular do departamento de Antropologia da PUC-SP;

(*) A preparação deste texto teria sido impossível sem a colaboração de Roseli Machado L. Nascimento, doutoranda do Programa de Estudos Pós-Graduados da PUC-SP, a quem muito agradeço.

Recebido em mar/2014

Aprovado em mar $/ 2014$ 